\title{
Reproductive strategies of two fungiid corals from the northern Red Sea: environmental constraints?
}

\author{
E. Kramarsky-Winter*, Y. Loya \\ Department of Zoology, George S. Wise Faculty of Life Sciences, Tel-Aviv University, Ramat Aviv, Tel Aviv 69978, Israel
}

\begin{abstract}
The dispersion patterns and reproductive strategies of 2 fungiid coral species (Fungia granulosa and Fungia scutaria) from the northern Red Sea are examined. F. scutaria is found in aggregations on shallow water patch reefs at depths of up to $5 \mathrm{~m}$. F. granulosa is more randomly distributed, on sandy substrates and rocky slopes, and is most abundant at depths of between 15 and $25 \mathrm{~m}$. Both species are gonochoric broadcasters, releasing gametes in the summer months, with gonad development beginning in early spring. The different reproductive strategies of the 2 species are expressed by the differences in size at maturity and length of reproductive period. Reproductive indices suggest a relatively long reproductive season for F. scutaria (June to September) and a shorter one for F. granulosa (July to August). F. scutaria spawns on the evening or evenings immediately following the full moon, whereas $F$. granulosa shows no correlation to lunar phase and spawns during daytime. In addition, a sexual dimorphism according to size was found for $F$. scutaria: small individuals $(2.5$ to $6.0 \mathrm{~cm}$ in length) were predominantly males, while very large individuals $(>9.0 \mathrm{~cm}$ in length) were all females. This indicates either protandry or that males reach sexual maturity at a smaller size than females. $F$. granulosa begins reproducing at a length of $5.5 \mathrm{~cm}$ (the diameter along the mouth axis) and no size related sexual dimorphism was found. The sex ratio of males to females in F. scutaria was 1.9:1 and in $F$. granulosa 1.1:1. Budding was more prevalent in the shallow-water-dwelling F. scutaria than in the deeper-water-dwelling $F$. granulosa. The differences in distribution pattern, reproductive timing, prevalence of budding and sex ratio found between the 2 species of fungiids indicate that the primary form of recruitment of the shallow water $F$. scutaria may be through asexual reproduction. These results suggest that the evolution of different reproductive strategies in closely related species may be in part the consequence of different environmental constraints.
\end{abstract}

KEY WORDS: Fungia granulosa Fungia scutaria $\cdot$ Red Sea $\cdot$ Reproductive strategies Gametogenesis

\section{INTRODUCTION}

The importance of environmental cues, such as habitat predictability, to the evolution of coral reproductive strategies has been suggested by a number of researchers (Loya 1976, Van Moorsel 1983, Harrison 1985, Szmant 1986, Stimson 1987, Harrison \& Wallace 1990). Coral species found in shallow water habitats that are subject to fluctuating physical conditions are usually small, short lived brooders, while related species in more predictable environments are longer lived, larger sized broadcasters (Loya 1976, Harrison \& Wallace 1990). Some scleractinian species found in different environments, or geographic locations, demon-

•E-mail: wintere@zoot.tau.ac.il strate mixed reproductive patterns, further pointing to the ties between environment and reproductive strategy (Harrison 1985, Harrison \& Wallace 1990, Fan \& Dai 1995). Harrison \& Wallace (1990) reasoned that, while the evolution of some aspects of coral reproductive strategy (such as gonochorism or hermaphrodism) may be genetically programmed, other aspects (such as length of reproductive season, spawning cue and size at maturity) may be plastic life history traits constrained by environmental factors.

Solitary free-living fungiid corals are abundant in the northern Red Sea in a variety of habitats from shallow, highly perturbed waters to deep calm waters. The dispersal patterns of these corals reflect such varied parameters as depth, sediment size, and hydrodynamic conditions on different portions of the reef 
throughout the world (Hoeksema 1989). Though much is known about the distribution patterns of these freeliving corals, only limited information is available on the reproductive strategies of fungiids in general, and none on the reproduction of fungiid species from the Gulf of Eilat (Abe 1937, Fadlallah 1983, Krupp 1983, Willis et al. 1985, Harrison \& Wallace 1990, Richmond \& Hunter 1990).

Thus in order to determine whether reproductive strategies in 2 closely related fungiid species are influenced by their environment, we investigated the gametogenic cycle and reproductive strategy of Fungia scutaria and Fungia granulosa from shallow and deep water in the Gulf of Eilat (Aqaba).

\section{MATERIALS AND METHODS}

The abundance and distribution pattern of the fungiids Fungia scutaria and F. granulosa were examined. The number of individuals of each species was counted from six $1 \mathrm{~m}^{2}$ quadrats randomly placed at each depth studied $(1,3,5,10,15,20$, and $25 \mathrm{~m})$ near the $H$. Steinitz Marine Biological Laboratory, Eilat, Israel. A standardized Morisita's Index of Dispersion (Ip) was used to ascertain the spatial distribution of both species (Krebbs 1989).

To determine the extent of budding in the 2 studied species, the number of individuals with buds and number of buds per individual were recorded under four $10 \mathrm{~m}$ line transects in each of the areas with greatest abundance of the 2 fungiid species (Loya 1972).

Monthly collections of 10 to 12 individuals of various sizes from each species were carried out for a period of 2 yr (1994 and 1995) from areas of high abundance. Sampling of Fungia scutaria was carried out at 2 to $3 \mathrm{~m}$ depth, and of $F$. granulosa at 15 to $20 \mathrm{~m}$ depth. Coral size was ascertained by measuring the diameter of the round species, F. granulosa, along the mouth axis, and the longest axis in the oval shaped F. scutaria. Wedge shaped fragments were broken off each individual and fixed in $4 \%$ formalin in sea water. The coral wedges were decalcified in formic acid and sodium citrate (Rinkevich \& Loya 1979), processed using a Citadel 2000 Tissue Processor, embedded in paraffin, sectioned and stained in Hematoxylin-Eosin. All the oocytes from sections of 3 gonads per individual were measured along their longest axis and mean oocyte size was calculated. Oocyte staging was a modification of that used by Van Veghel (1994a): In stage 1, discernible stem cells were visible in thin gonads, but no differentiation of oocyte or spermatogonia was observed. In stage 2, primordial oogonia with large nuclei and a small amount of cytoplasm were visible. Stage 3 oocytes had nuclei with visible nucleoli. Stage 4 fea- tured eggs ready for spawning Spermatogenesis was recorded at stage 2 , when spermatogonia were visible as small groups of cells in the mesoglea. At stage 3, spermatozoa were visible, and at stage 4 sperm with flagellae were visible. In both species a sex ratio was calculated using pooled samples from the 2 study years. Only individuals from the peak gametogenic months, prior to spawning, were counted.

During the reproductive months, whole individuals were collected and were kept in well aerated aquaria for observation of spawning.

\section{RESULTS}

\section{Abundance and spatial distribution patterns}

The abundance and distribution patterns of the studied fungiids are shown in Fig 1. Fungia scutaria was found only in aggregates and in shallow waters on and around coral knolls at depths of 0.5 to $5 \mathrm{~m}$ (Fig. 1). At these depths they exhibited a clumped distribution according to Morisita's Index (Ip $=0.605$ at $1 \mathrm{~m}$ depth, Ip $=0.521$ at $3 \mathrm{~m}$ depth and $\mathrm{Ip}=0.534$ at $5 \mathrm{~m}$ depth). The large standard deviations found (Fig. 1) are a result of their highly aggregated distribution. F. granulosa was found randomly dispersed (Morisita's Index, Ip $<0.5$ at all depths) on sandy substrates as well as on rocky slopes from $5 \mathrm{~m}$ to over $25 \mathrm{~m}$ depth, though they were most abundant on rocky slopes at depths of 15 to $25 \mathrm{~m}$ (Fig. 1).

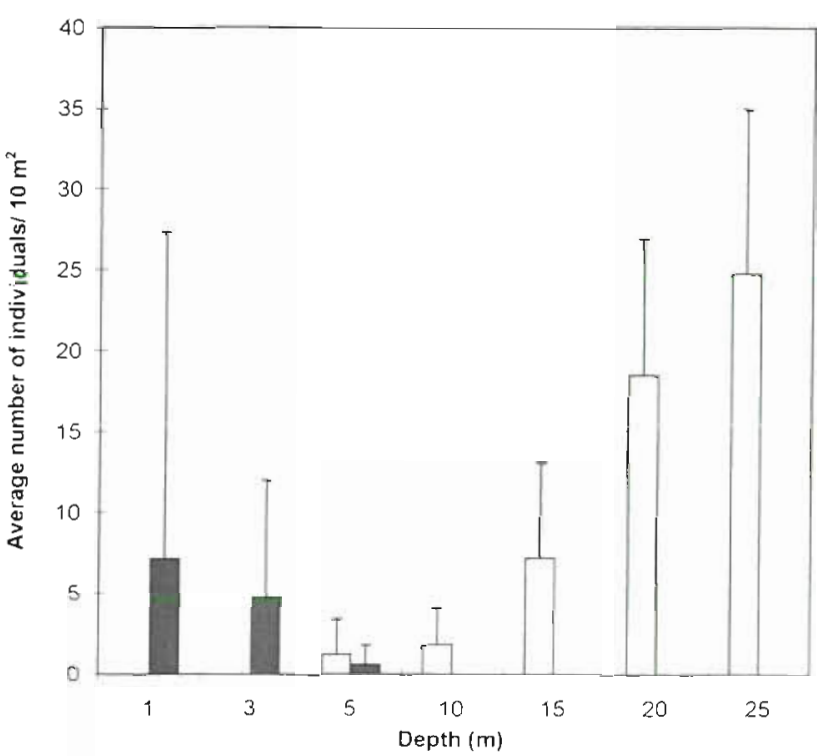

Fig. 1. Fungia granulosa and F. scutaria. Average number of individuals ( $\mathrm{SD}$ ) at various depths at the study sites in the northern Gulf of Eilat. Shaded bars: F. scutaria; open bars: $F$. granulosa 


\section{Gametogenesis}

Fungia granulosa were gonochoric (Fig. 2). Only specimens over $5.5 \mathrm{~cm}$ in diameter developed gonads, even during peak reproductive months (Fig. 3a). Oocytes and spermaries developed in the incomplete septae adjacent to the mesenterial filaments. The gonads were oriented along the septal axis. Stem cells (stage 1) were first discernible in gonads in late February, early March. Oogonia (stage 2; Fig. 2a) were visible in April and ripe oocytes (stage 3) were visible in May-June (Fig. 2b). Mature oocytes (stage 4) were found in July-August, when spawning occurred (Fig. 2c). Average oocyte size at maturity was $130 \pm 18.9 \mu \mathrm{m}$, maximal size was $150 \mu \mathrm{m}$, and all oocytes seemed synchronous in size and stage (Fig. 4). There was a 1 mo lag in male gonad development, and spermatocytes were visible at the end of April. Spermatogenesis began with small groups of cells in the mesoglea (stage 2; Fig. 2d), which developed into spermatocytes (stage 3; Fig. 2e) and eventually into sperm (stage 4; Fig. 2f). No morphological sexual dimorphism or related size differences were visible in this species (Fig. 3a). During the peak gametogenic months the male to female ratio was 1.1:1 ( $\mathrm{n}$ pooled $=60$ ).

Fungia scutaria were also gonochoric (Fig. 5). Female gonads began developing in February, and male gonads were visible in March. Stem cells were visible in the mesoglea in the gonads in late February, early March. Oogonia (stage 2; Fig. 5a) were visible in late March. Oocytes (stage 3) were visible in May and mature oocytes and eggs (stage 4) were visible in June (Fig. 5b). Testes with spermatogonia began developing during late April, early May (Fig. 5c). Mature sperm were visible in May-June (Fig. 5d). During the peak reproductive period even very small individuals of $2.5 \mathrm{~cm}$ length were sexually mature (Fig. 3b). In addition all the collected individuals under $5.0 \mathrm{~cm}$ length were males and all those over $9.0 \mathrm{~cm}$ were females (Fig. 3b).

A variety of oocyte sizes were found in the gonads during oogenesis, even at peak reproduction (Fig. 4), indicating multiple spawning events. During peak reproductive months, maximum oocyte size was $200 \mu \mathrm{m}$, while the mean was $126 \pm 63.2 \mu \mathrm{m}$. The ratio of males to females during peak gametogenic months prior to spawning was 1.9:1 ( $\mathrm{n}$ pooled $=64$ ).

There was a lag of approximately 1 mo in the gametogenic cycle between the 2 species, though there was a slight overlap in the peak spawning months, with Fungia scutaria developing before F. granulosa (Fig. 4)

\section{Spawning}

Spawning in both coral species occurred in the summer months (Fig. 4), Gametes were released through the mouths of the corals in spurts. Peak reproductive effort in Fungia scutaria was from June through September, and spawning was observed beginning in the late afternoon to early evening (17:00 to $18: 00 \mathrm{~h}) 1$ to $4 \mathrm{~d}$ after full moon. The spawning process was incomplete, and gonads of female corals collected after spawning contained a number of oocytes. In addition, male gonads contained spermaries at different stages of development (Fig. 5d).

In Fungia granulosa, peak reproduction occurred from July through August and gamete release did not seem to correspond to the lunar phase. Spawning was observed at different times of the day, and occurred in several spurts. Released oocytes were opaque and granular, negatively buoyant and lacked zooxanthellae. Spawned individuals retained very few oocytes in the gonads, indicating complete spawning in this species.

\section{Asexual reproduction}

Individuals with buds were found in both species, though budding was more prevalent in the shallow water Fungia scutaria. In $F$, granulosa there was an average of $2.5 \pm 2.0$ buds coral $^{-1}$ under each $10 \mathrm{~m}$ line transect. In F. scutaria the average number was $19.8 \pm$ 31.1 buds $\mathrm{coral}^{-1}$. No correlation between number of buds per coral and coral size was found ( $p>0.05)$.

\section{DISCUSSION}

Environmental conditions may influence sexual reproduction by exerting selective pressure on such processes as synchrony, timing and modes of reproduction. Exogenous factors can interact with endogenous biorhythms to cause local shifts in reproductive strategies (Giese \& Pearse 1974). Corals that dwell in shallow waters are susceptible to high irradiation, periodic flooding and sedimentation, and may have evolved a variety of adaptive responses to maximize their success in these environments. The greater environmental stability found in deeper waters might be conducive to the evolution of different reproductive strategies in deep and shallow water species. Indeed, a number of authors have hypothesized that, in response to environmental unpredictability and stress, organisms evolved $r$-strategy characteristics such as a prolonged reproductive season, early sexual maturity, and repeated spawnings, which increase the species' chance for reproductive success in these environments (Giesel 1976, Loya 1976, Stimson 1978). Indeed these characteristics are common in shallow water corals (Loya 1976, Stimson 1978, Shlesinger \& 


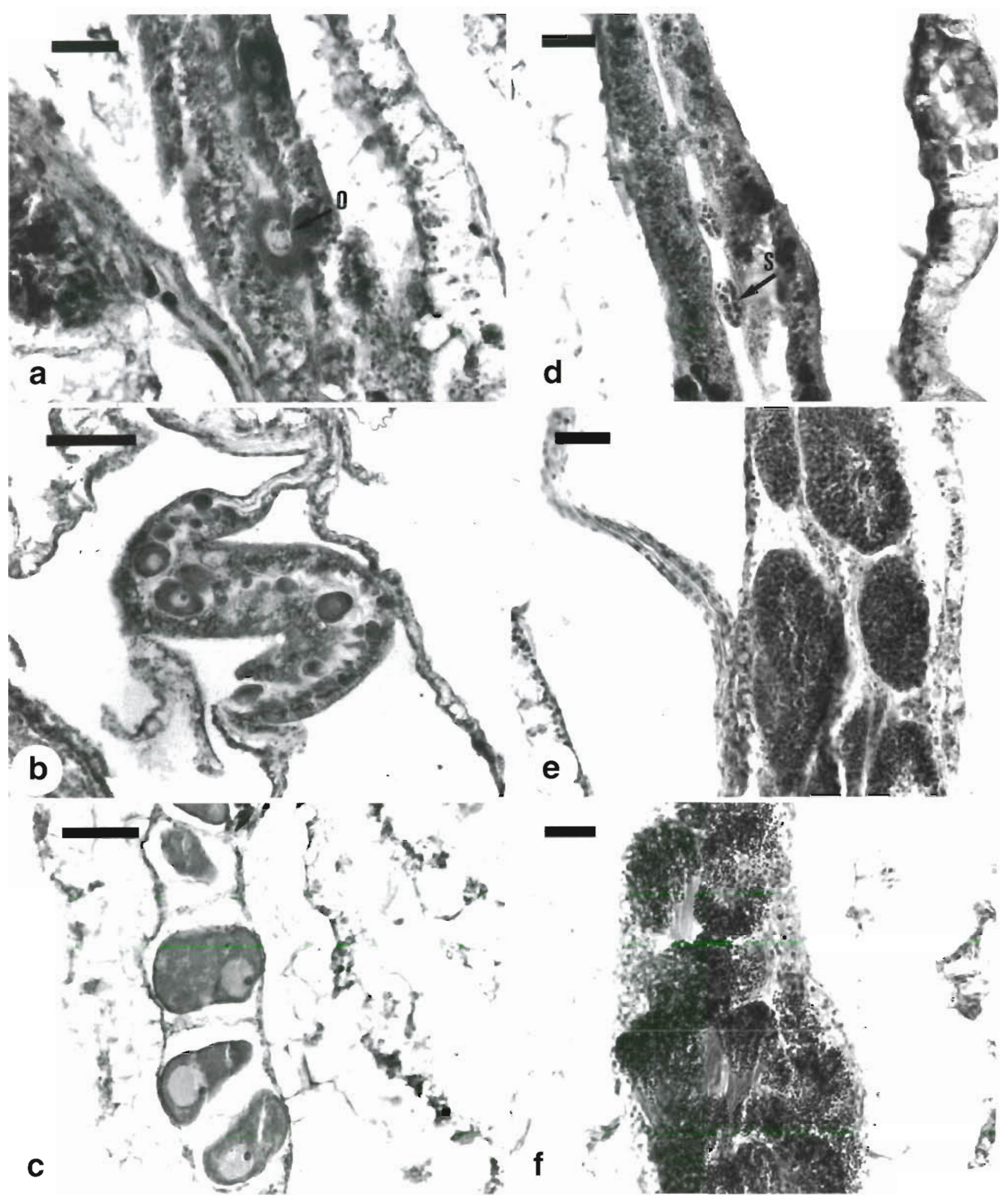

Fig. 2. Fungia granulosa. Photomicrograph of gametogenesis. (a) Stage 2 oogonia (0) in the developing gonad. Scale bar: $25 \mu \mathrm{m}$. (b) Developing oocytes. Scale bar: $100 \mu \mathrm{m}$. (c) Developed oocytes. Scale bar: $120 \mu \mathrm{m}$. (d) Stage 2 spermatogonta (s) in developing gonad. Scale bar: $20 \mu \mathrm{m}$. (e) Developing spermatocytes. Scale bar: $30 \mu \mathrm{m}$. (f) Developed sperm in mature gonad. Scale 

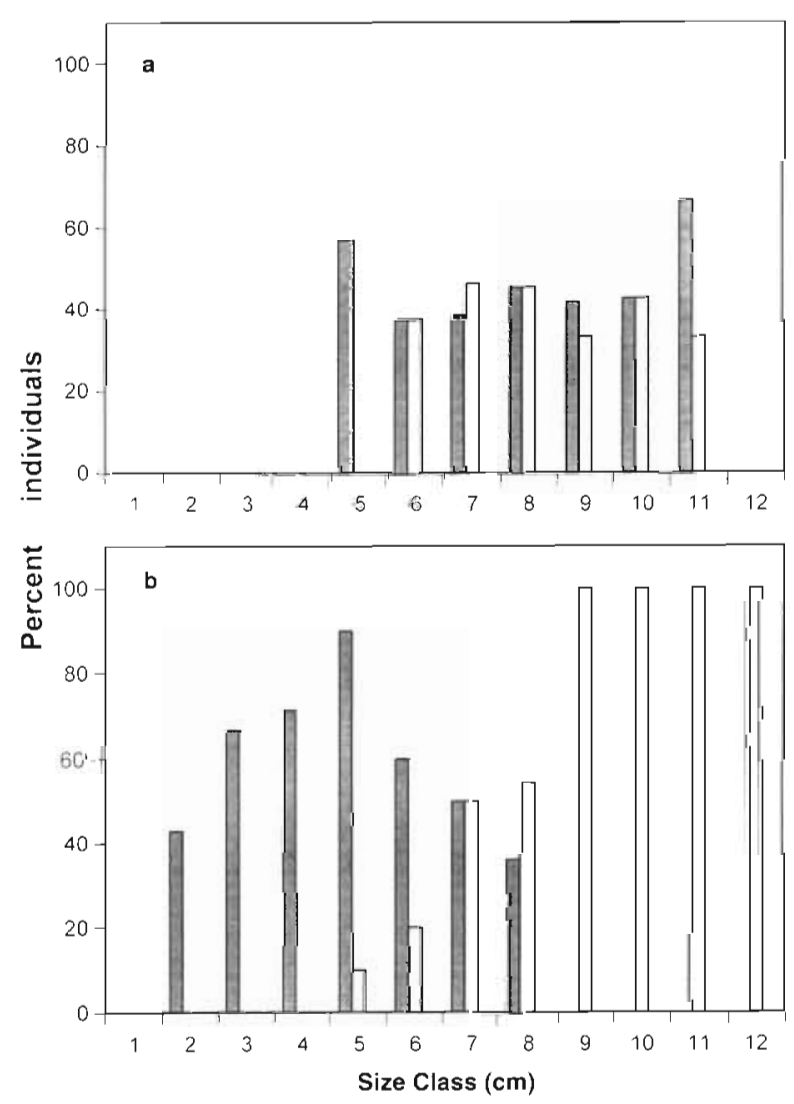

Fig. 3. Fungia granulosa and F. scutaria. Size class distribution of male and female fungiids collected during the peak reproductive months in the study area. Open bars: females; solid bars: males. (a) F. granulosa $\mathrm{n}=80$. (b) F. scutaria; $\mathrm{n}=100$

Loya 1985, Szmant-Froelich et al. 1985, Richmond \& Hunter 1990).

Van Veghel $(1994 \mathrm{a}, \mathrm{b})$ showed that the shallow water population of the colonial coral Montastrea annularis begins reproducing at a smaller size than the deeper water population. Acosta \& Zea (1997) showed differences in the length and timing of reproduction in populations of Montipora cavernosa found in different geographic locations. They attributed these differences to different local seasonal stresses as well as to physical location. Similar differences in length of spawning period and size at

Fig. 4. Fungia granulosa and F. scutaria. Oogenetic cycle during the years 1994 and 1995. ( ) Average oocyte diameters in F. scutaria; $(\Delta)$ average oocyte diameters in $F$. granulosa. Bars: standard deviations maturity were found in the shallow water colonial coral Agaricia humilis and its deeper water congener Agaricia agaricites (Van Moorsel 1983). Although both coral species studied in this work were found to be gonochoric broadcasters reproducing during summer, they differed in size at maturity, spawning synchrony, and timing. The small size at maturity, repeated synchronous spawnings, and prolonged spawning season found in Fungia scutaria may aid this coral in overcoming the rigors of its shallow water habitat, in which sporadic catastrophes cause large scale death of large individuals (see Jokiel et al. 1993). In contrast, the congeneric F. granulosa, which is abundant in calmer deeper water (at depths of 15 to $25 \mathrm{~m}$ ), begins reproducing at a larger size than $F$. scutaria, concentrates its reproductive efforts into a shorter period, and has only 1 or 2 spawning events. These features may place the reproductive strategy of this species closer to the $K$ endpoint of the $r-K$ continuum (Loya 1976)

The sex ratio in a population with random matings is usually 1:1 (Maynard-Smith 1978). Skewing from this norm indicates either sampling bias or clonal propagation (Harrison \& Wallace 1990). The skewed sex ratio of $1: 1.9$ found in the Fungia scutaria population may thus be explained either by clonal propagation, known to occur in fungiids (Wells 1966, Harrison \& Wallace 1990, Kramarsky-Winter \& Loya 1996), or by sampling bias, such as unwitting collection of individuals that may actually have been clonemates. In contrast, the sex ratio found in the deeper-water-inhabiting F. granulosa, was close to $1: 1$, indicating that this species relies less on clonal propagation than its shallow water congener.

Asexual reproduction is thought to be a mechanism of local dispersion in a number of coral species in

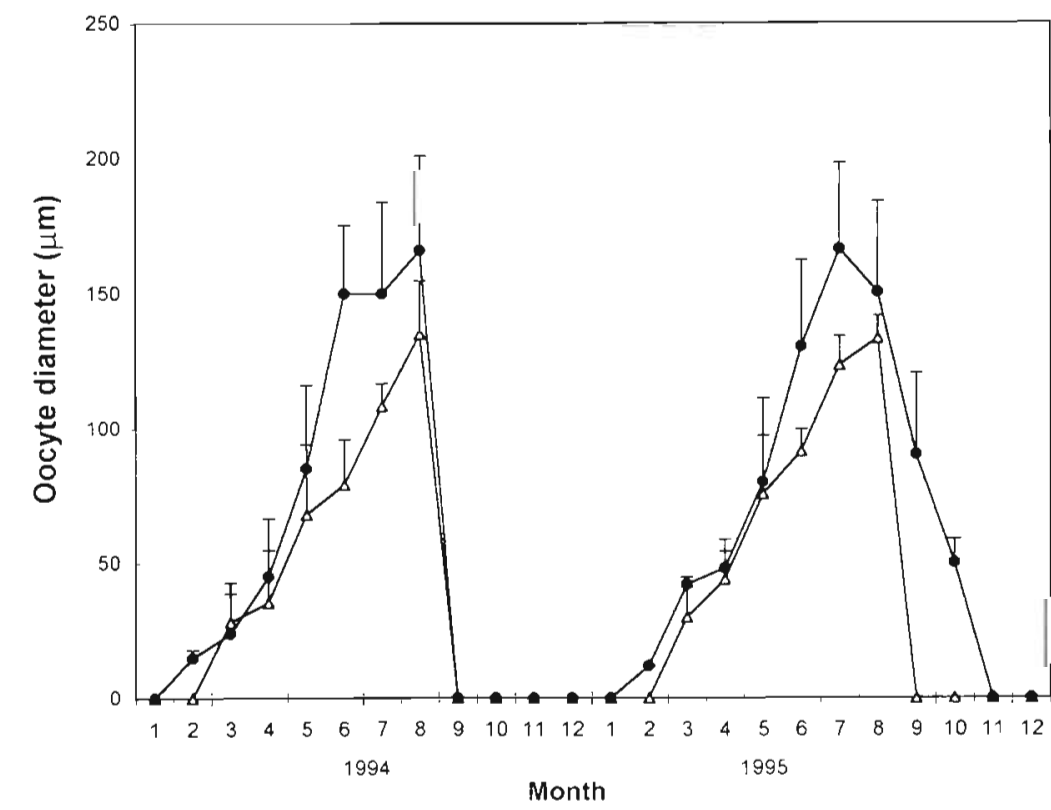



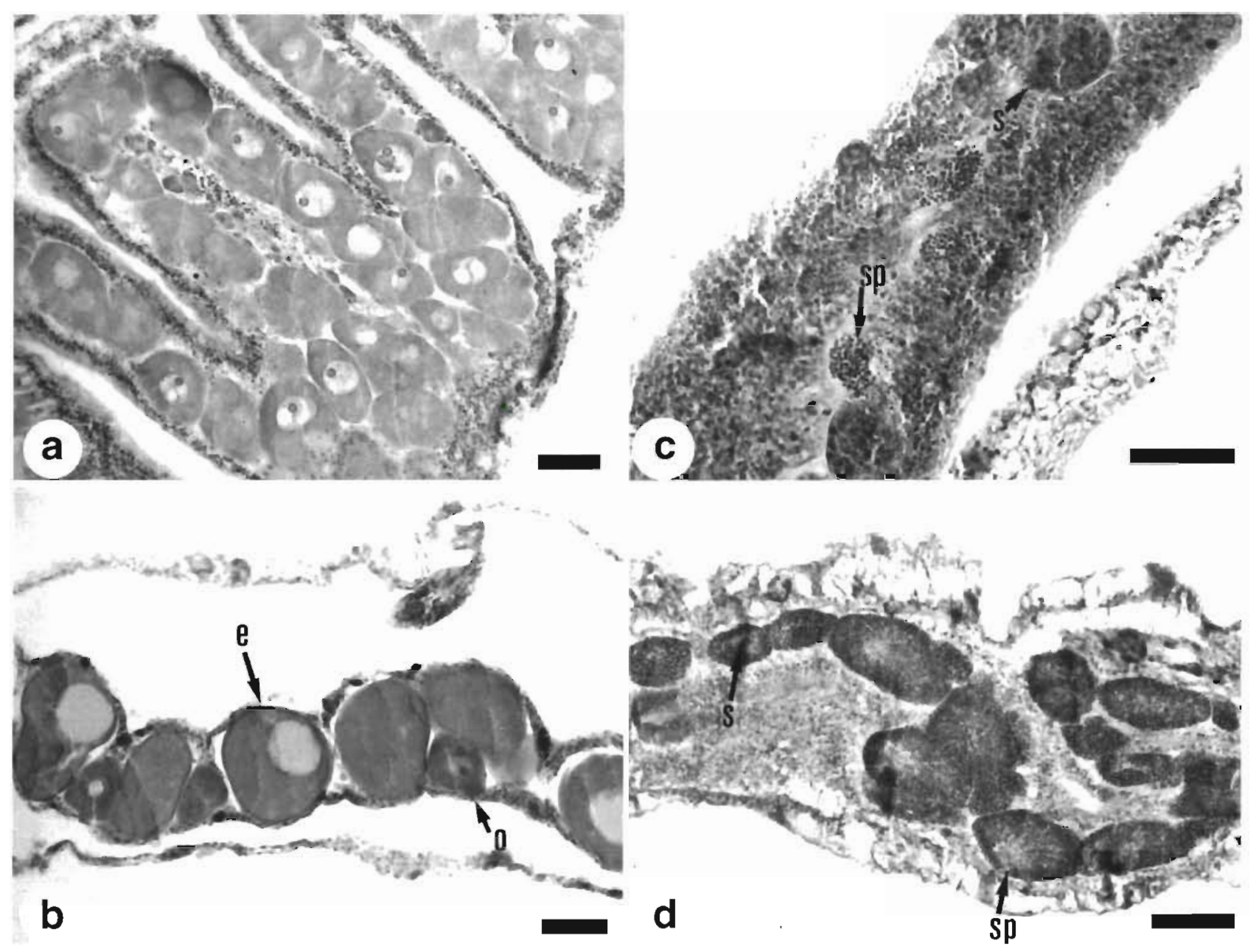

Fig. 5. Fungia scutaria. Photomicrograph of gametogenesis. (a) Developing oocytes. (b) Developed oocytes prior to release 0 : developing oocytes; e: developed eggs prior to release. (c) Developing testes. (d) Testes prior to sperm release. sp: mature sperm; s: developing spermatocytes. Scale bars: $100 \mu \mathrm{m}$

highly disturbed environments (Kojis \& Quinn 1981, Highsmith 1982, Harrison \& Wallace 1990). It has recently been shown that, in very shallow waters, even colonial species not previously known to do so reproduce asexually to enhance local recruitment (Kramarsky-Winter et al. 1997). Populations of Fungia scutaria are known to withstand periodic density independent mortality caused by periodic catastrophes and were shown to 'resurge' through budding of remnant adult tissues (Jokiel et al. 1993, Krupp et al. 1993, Kramarsky-Winter \& Loya 1996). The amount of budding occurring in this shallow water coral population strengthens the premise that, in addition to sexual reproduction, the $F$ scutaria population studied here relies on clonal propagation as a means for local recruitment. This premise is further strengthened by this coral's highly aggregated distribution. Moreover similar aggregated distribution patterns have been reported for the fungiids Diaseris distorta and $D$. fragilis, which are known to reproduce asexually by natural fragmentation (Goreau \& Yonge 1968, Nishihara \& Poung-In 1989). In comparison, the smaller extent of budding occurring in $F$. granulosa, in addition to its more random distribution pattern, indicates that it relies less on asexual reproduction than its shallow water congener.

Another difference in reproductive characteristics between the 2 species studied is the size related dimorphism found in Fungia scutaria but not in F. granulosa. Although to date protandry has not been reported in scleractinian corals, this could be one interpretation for this dimorphism. Indeed, although Krupp (1983) suggested this possibility, he noted that without long-term monitoring of individuals it is impossible to determine this for sure (Krupp pers. comm.). Moreover, the size related dimorphism in shallow water corals may be 
due to males maturing earlier than females and may reflect an energetic trade-off between reproduction and growth (Harrison \& Wallace 1990). This reproductive strategy is similar to that of shallow water hermaphroditic corals where early investment in testes development allows for sex to commence without the energetic expense of egg production, permitting these corals to grow to a larger safer size before developing female gonads (Hall \& Hughes 1996). Another possible explanation of why none of the large individuals collected were males is that only a small number of very large individuals of $F$. scutaria were found in the study area, which may have caused sampling bias

Though it is likely that many aspects of the reproductive patterns in the 2 fungiid species studied here have a phylogenetic base, some of the differences in reproductive patterns found in species from differing habitats may be due to the differences in the environmental regimes they encounter. Reproductive strategies of fungiid species found in deeper calmer habitats may be constrained by different environmental factors than those constraining reproductive strategies of species from shallow water habitats. These differences may provide clues regarding some of the factors involved in the evolution of reproductive strategies.

Acknowledgements. We thank Dr R. Ben Hillel for her assistance with the histology, Dr I. Brickner for his helpful comments, and Ms Naomi Paz for her editorial assistance. This study was supported by the Robert Raynor Chair for Environmental Conservation Research

\section{LITERATURE CITED}

Abe N (1937) Post larval development of the coral Fungia actiniformis var. palawensis Doderlein. Palao Trop Sta Stud 1:73-93

Acosta A, Zea S (1997) Sexual reproduction of the reef coral Montastrea cavernosa (Scleractinia: Faviidae) in the Santa Mara area, Caribbean coast of Columbia. Mar Ecol Prog Ser 128:141-148

Chorensky EA, Peters EC (1987) Sexual reproduction and colony growth in the scleractunian coral Porites asteroides. Biol Bull 172:161-177

Fadlallah YH (1983) Sexual reproduction, development and larval biology in scleractinian corals. A review. Coral Reefs 2:129-150

Fan TY, Dai CF (1995) Reproductive ecology of the scleractinian coral Echinopora lamellosa in northern and southern Taiwan. Mar Biol 123:565-572

Giese AC, Pearse JS (1974) Introduction: general principles. In: Giese AC. Pearse JS (eds) Reproduction of marine invertebrates I. Academic Press, New York, p 1-49

Giesel JT (1976) Reproductive strategies as adaptations to life in temporally heterogeneous environments. Annu Rev Ecol Syst 7:57-79

Goreau TF, Yonge CM (1968) Coral community on muddy sand. Nature 217(5127):421-423

Hall VR, Hughes TP (1996) Reproductive strategies of modular organisms: comparative studies of reef-building corals.
Ecology $77(3): 950-963$

Harrison PL (1985) Sexual characteristics of scleractinian corals: systematic and evolutionary implications. Proc 5th Int Coral Reef Congr 4:337-342

Harrison PL, Wallace CC (1990) Reproduction, dispersal and recruitment of scleractinian corals. In: Dubinsky $Z$ (ed) Ecosystems of the world, Vol 25: coral reefs. Elsevier, Amsterdam, p 133-207

Highsmith RC (1982) Reproduction by fragmentation. Mar Ecol Prog Ser 7:207-226

Hoeksema BW (1989) Taxonomy, phylogeny and biogeography of mushroom corals (Scleractinia: Fungiidae). Zool Verh 254:1-295

Jokiel PL, Hunter CL, Taguchi S, Watari L (1993) Ecological impact of a fresh water 'reef-kill' in Kanehoe Bay, Oahu, Hawaii. Coral Reefs 12:177-184

Kojis B, Quinn N (1981) Reproductive strategies in four species of Porites (Scleractinia). Proc 4th Int Coral Reef Symp 2:145-151

Kramarsky-Winter E, Fine M, Loya Y (1997) Coral polyp expulsion. Nature 387:137

Kramarsky-Winter E, Loya Y (1996) Regeneration versus budding in fungiid corals: a trade-off. Mar Ecol Prog Ser 134: $179-185$

Krebbs E (1989) Ecological methodology. Harper Collins Publishers, London, p 149-153

Krupp DA (1983) Sexual reproduction and early development of the solitary coral Fungia scutaria (Anthozoa: Scleractinia). Coral Reefs 2:153-164

Krupp DA, Jokiel PL, Chartrand TS (1993) Asexual reproduction by the solitary scleractinian coral Fungia scutaria on dead parent coralla in Kanehoe Bay, Oahu, Hawaiian Island. Proc 7th Int Symp Coral Reefs 1:527-534

Loya Y (1972) Community structure and species diversity of hermatypic corals at Eilat, Red Sea. Mar Biol 13:100-123

Loya Y (1976) The Red Sea coral Stylophora pistillata is an $r$ strategist. Nature 259:478-480

Maynard-Smith J (1978) The evolution of sex. Cambridge University Press, Cambridge

Nishihara M, Poung-In S (1989) Distribution and population structure of a free living coral, Diaseris fragilis, at Khang Khao Island in the Gulf of Thailand. Galaxea 8:271-282

Richmond RH, Hunter CL (1990) Reproduction and recruitment of corals: comparisons among the Caribbean, the Tropical Pacific, and the Red Sea. Mar Ecol Prog Ser 60: $120-203$

Rinkevich B, Loya Y (1979) The reproduction of the Red Sea coral Stylophora pistillata. I: Gonads and planulae. Mar Ecol Prog Ser 1:133-144

Shlesinger Y, Loya Y (1985) Coral community reproductive patterns: Red Sea versus Great Barrier Reef. Science 228: $1333-1335$

Stimson JS (1978) Mode and timing of reproduction in some common hermatypic corals of Hawaii and Enetwetak. Mar Biol 48:173-184

Szmant AM (1986) Reproductive ecology of Caribbean reef corals. Coral Reefs 5:43-53

Szmant-Froelich A, Ruetter M, Riggs L (1985) Sexual reproduction of Favia fragum (Esper): lunar patterns of gametogenesis, embryogenesis and planulation in Puerto Rico. Bull Mar Sci 37(3):880-892

Van Moorsel GWNM (1983) Reproductive strategles un two closely related stony corals (Agaricia, Scleractinia). Mar Ecol Prog Ser 13:273-283

Van Veghel MLJ (1994a) Reproductive characteristics of the polymorphic Caribbean reef building coral Montastrea annularis. I. Gametogenesis and spawning behavior. Mar 
Ecol Prog Ser 109:209-219

Van Veghel MLJ (1994b) Reproductive characteristics of the polymorphic Caribbean reef building coral Montastrea annularis. II. Fecundity and colony structure. Mar Ecol Prog Ser 109:221-227

Wells JW (1966) Evolutionary development in the scleractin-

Editorial responsibility: Otto Kinne (Editor).

Oldendorf/Luhe, Germany ian family Fungiidae. In: Reese WJ (ed) The Cnidaria and their evolution. Academic Press, London, p 223-246

Willis $\mathrm{BL}$, Babcock RC, Harrison PL, Oliver JK, Wallace CC (1985) Patterns in the mass spawning of the corals on the Great Barrier Reef from 1981-1985. Proc 5th Int Coral Reef Congr 4:343-348

Submitted: December 29, 1997; Accepted: July 31, 1998 Proofs received from author(s): November 2, 1998 